ISSN: 2277-3754

ISO 9001:2008 Certified

International Journal of Engineering and Innovative Technology (IJEIT)

Volume 10, Issue 3, September 2020

\title{
Aspects of the use of nanotechnology and nanomedicine in medicine
}

Muhamet Avdyli, Era Kastrati

Department of Computer Science and Engineering, University of Business and Technology - UBT, Kosovo

\begin{abstract}
The objective of this paper is to discuss aspects of the application of the nanotechnologies, especially in medicine, in these days. The design, development and implementation by manipulating form and size on a nanometer-scale of structures, equipment and systems are nanotechnologies. Nanomedicine is the special division Concerned with medicine research of nanotechnology. Nanomedicine is a medicine field which uses nanotechnology knowledge and instruments for disease prevention and treatment. Nanomedicine includes the use for the detection or activation of nanoscale materials in a living organism such as nanoparticles and nanaorobots [1]. Nanotechnology is considered completely new, but it is definitely not the only field concerned with atoms and molecules. I have now shown my own actions and manipulation and quantum mechanics to be a totally minor science in different fields of physics, chemistry and biology with atoms and molecules.
\end{abstract}

Index Terms - Nanotechnology, nanomedicine, nanoscale, nanoparticle, nanorobots.

\section{INTRODUCTION}

Physicists and engineers who were primarily concerned to create objects or components for other devices with greater precision in terms of the use of a computer made of components manufactured at a certain level of accuracy made initial awareness of the field of nanotechnology. This nanotechnology is now regarded as "top-down"[2].

Winfred Phillops said, "You have to be able to invent things, you have to be able to analyze things and you have to be able to handle things smaller than imagined in ways that have not been done before"

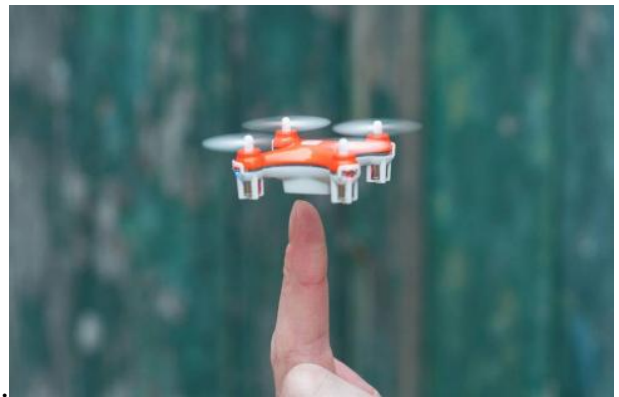

Fig.1 Nanotechnologic tool, nano drone.

Theory of nanotechnology was first introduced in 1959 by physicist Faynman, who at dinner said, at the end there is plenty of room, "stressing that this is a trend that should not be avoided.

Manuscript received: 22 August 2020

Manuscript received in revised form: 19 September 2020

Manuscript accepted: 03 October 2020

Manuscript Available online: 15 October 2020
He suggested that nanomachines, nanorobots, and nanoprocessors could grow a broad range and be used to produce large amounts of ultra-small computers and various nanorobots, using automatically precise microscopic instruments and development tools [3].

\section{WHAT'S NANOMEDICINE?}

The ordinary human mind is hard to comprehend nanotechnology, because it is entirely different. The research, engineering and technology carried on in nanoscales, of around 1-100 nanometres, comprises nanotechnology basically. One nanometer is a million times shorter than the ant's length. A paper sheet is roughly 100,000 nanometres. Normal ratio of one metre to one nanometer from Earth to a child's body [4]. Nanomedicine is the scientific and technological area in which traumatic diseases and accidents are diagnosed, treated and avoided, pain relieved, people's health sustained and improved, molecular methods used and human body molecules used.Nano-technology and medicine converge to create new therapies and strengthen existing ones. The emerging discipline of Nanomedicine Nanostructures of the same size as bimolecular are manipulated to interact with human cells for nanomedicine [4].

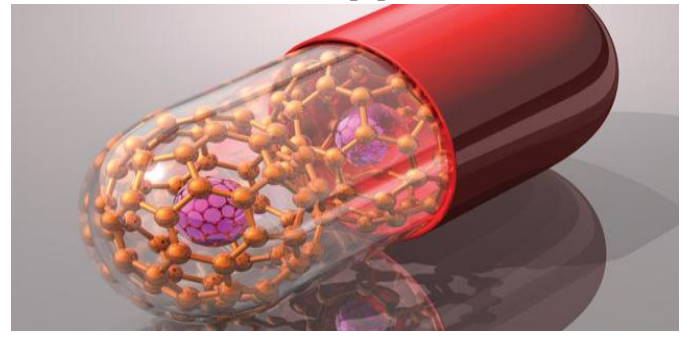

Fig. 2 Capsule that can digest in the body.

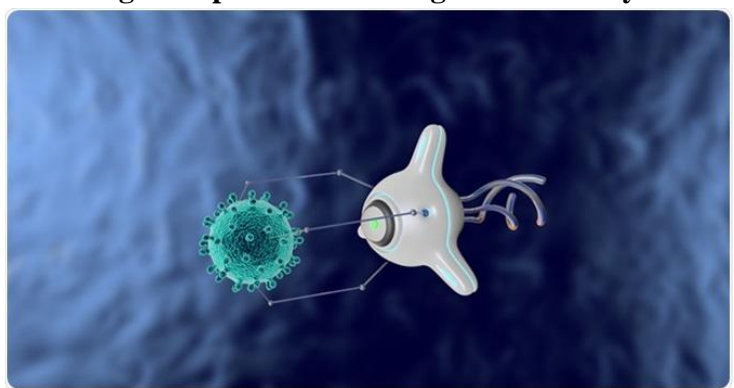

Fig.3. Nanorobot that leak into blood.

\section{THE FUTURE OF NANOTECHNOLOGY}

Soluble capsules include sensors and cameras, which are changing the world. In the following we will present some of these capsules as well as their use. Some of them are already on the market, while others are on the way out. Scattered capsules from nanoparticles promise for targeted treatment of 
ISSN: 2277-3754

\section{ISO 9001:2008 Certified}

International Journal of Engineering and Innovative Technology (IJEIT)

Volume 10, Issue 3, September 2020

many diseases, including cancer. However, the particles have to be injected into patients, which have limited their usefulness so far. Now, some researchers have developed a new type of nanoparticle that can be taken orally or through the digestive tract, allowing patients to simply take one capsule instead of injections. [3] Here are some of these capsules:

\section{Camera Capsule}

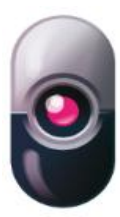

In 2001 PillCam was developed as the first soluble camera, which after entering the body through the throat, does its job (eg looks at the work of the stomach, heart, throat) and digests.

\section{Flutter Capsule}

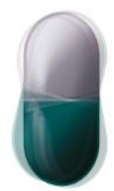

Vibrating capsules help contract muscles to start digestion. Effectively helps constipation and cleanses the body, without side effects.

\section{Narcotics detection capsule}

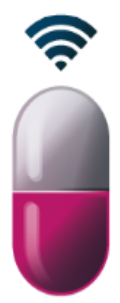

Each capsule contains a sensor that transmits information through a special garment worn by the patient. But because of its sensitivity, it costs around $\$ 290$ billion. But for many people it is a hindrance because personal data is shown, which can create insecurity.

\section{Atmo gas capsule}

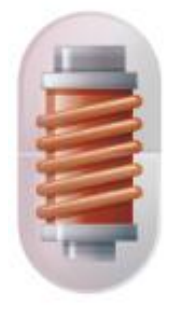

The membrane allows gases to enter the capsule. The sensors detect the level of oxygen, hydrogen and $\mathrm{CO} 2$ and thus detect the presence or excess of gases in certain parts of the

\section{Smart sensor capsule}

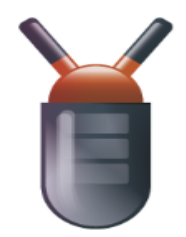

Y-shaped capsules are stored in the stomach for about a month. Sensors detect vital signs for diagnosis and monitor diseases.

\section{Big data availability}

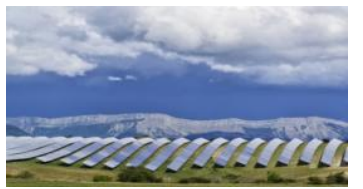

\section{Sensors everywhere}

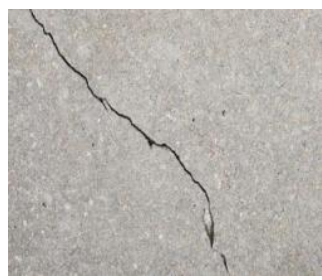

\section{BLOOD FLOW CHANGES}

Sometimes we have some sort of diseases, which make us feel bad but we don't know the problem. Now it is much easier. You just have to take a nanorobot, in a size of a pill and your body is shown in the monitor. In the next 5 or so years, our blood will be flowing with tiny nanorobots to help us avoid getting sick. [4]

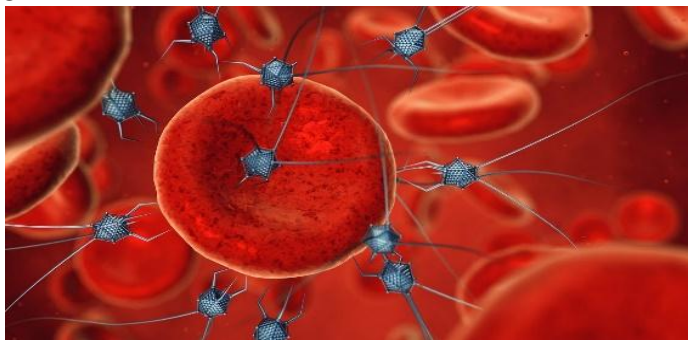

Fig 4. Nanorobots in erythrocytes.

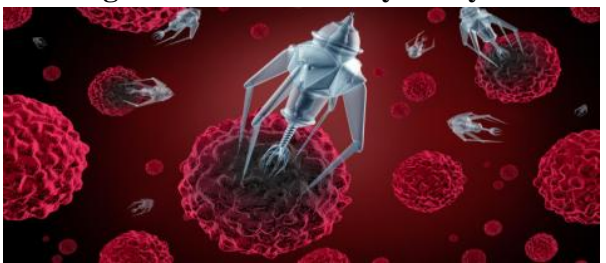

Fig 5. Illustration of cancer detection.

By all means, the researchers predict that after 5 years, we will have injected nanorobots into our bloodstream from where it will become a much more common practice in the medical world. In addition to cancer, people will be able to cure other issues by making nanorobots an optimal way to improve your living conditions.

\section{DISADVANTAGES OF NANOTECHNOLOGY}

As the technology is breaking every border possible, people are getting worried and worried because of it's big impact on everyday lives.Nanoparticles have also been examined for their impact on the heart and blood vessels. 
ISSN: 2277-3754

ISO 9001:2008 Certified

International Journal of Engineering and Innovative Technology (IJEIT)

Volume 10, Issue 3, September 2020

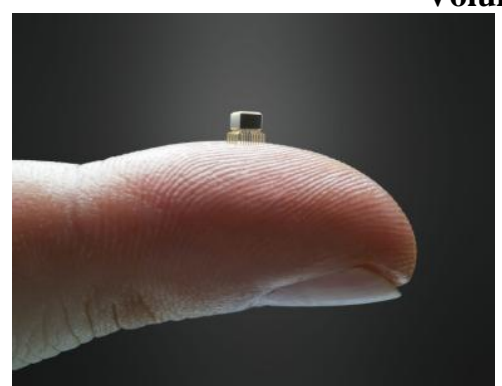

Fig 6. Small nanorobot, but expensive.

More specifically, the arming of nanotechnology could be feasible. It will be easier to develop nuclear bombs and new weapons. One alternative is the so-called "smart bullet, "a machine bullet that is very precisely tracked and targeted. These inventions can prove to the military's advantage, but the consequences are serious if they fall into the wrong hands.

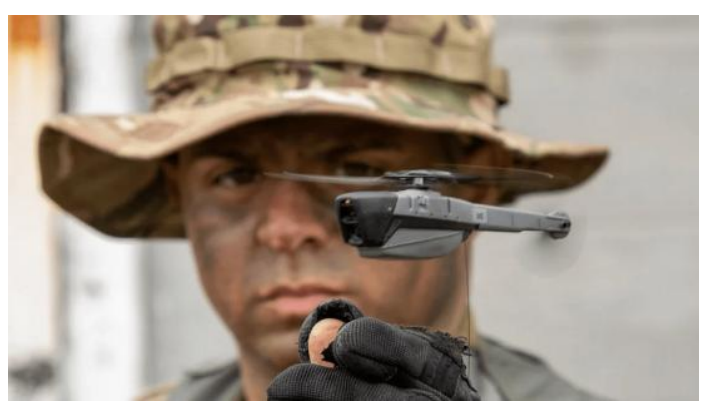

Fig 7. Nanotechnonolgy in army.

\section{CONCLUSION}

This research has shown how nanotechnology-when used in a deliberately small scale, the use of matter can offer great advantages, just like any useful technology.

\section{REFERENCES}

[1] Sara Soares, Joao Sousa, Alberto Pais, Carla Vitorino," Nanomedicine: Principles, Properties, and Regulatory Issues", Journal of Frontier in chemistry, Volume 6, pp: 1-15, August 2018.

[2] Doyle, D. John, "Medical Nanotechnology and Nanomedicine (Perspectives in Nanotechnology)", Anesthesia \& Analgesia, Volume 117, Issue 5, pp: 1265-1266, Nov 2013.

[3] Saeid Kargozara, Masoud Mozafari, "Nanotechnology and Nanomedicine: Start small, think big", Materials today Proceedings, Volume 5, Issue 7, Part 3, pp: 15492-15500, 2018.

[4] Mahya Safarzadeh, Shahed Taheri and Gity Mir Mohamad Sadeghi, "Highly Monodisperse Chitosan Nanoparticles Prepared by a Combined Triple Method for Potential Use as Drug Carriers", International journal of nanomaterials, nanotechnology and Nanomedicine, vol 3 ,issue 1,pp:1-6,2017.

\section{AUTHOR BIOGRAPHY}

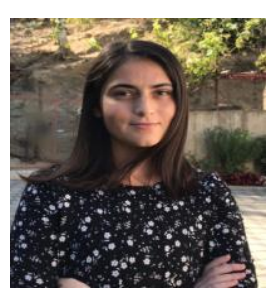

Era Kastrati: She is studying bachelor degree at UBT- University of Business and Technology in Computer Sciences and Technology department. She is looking forward to continue her studies abroad as an exchange student, in website programming branch. She finished her primary school at

'Xhelal Sopi' as an excellent student. Later she got a scholarship at 'Hasan Nahi' college in Prishtina, where she continued her high school studies. She finished some training in HTML, CSS and Java. She is interested in software development and working to build up her skills and knowledge around building various software, utilizing technology stacks such as Java, PHP etc.

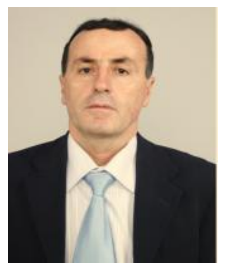

Muhamet Avdyli: Professor D.Sc in System of Information's, he graduated Electrotechnics at University of Prishtina where he got the engineer title, he got his master in Satellite Telecommunications at the same university, worked as a professor in some colleges and universities, momentally he is working at UBT- University of Business and TechnologyDepartment of Computer Science and Engineering. He has a big number of publications in journals and science conferences, especially in information systems. Some of these publications are: 'Requirements, Hardware and Software Description of Server AVL Triola (AVLT) for Tracking from the Distance and Managing the Transportation Vehicle Float for Passengers and Goods', 'The use of Intelligent System in transport and concrete benefits when using this system in context of saving fuel', 'Some Results with Economic and Managerial Character when using a Telemetric System in the Transportation Process in a Transport Business' , 'Protection of Personal Data and Security of information. The challenge of Kosovo Institutions that do not Endure the Institutional Vacuum' etc. 